\title{
O USO INICIAL DO SOFTWARE WEBQDA PARA APOIAR A CONDUÇÃO DE UMA TESE
}

\author{
Valberto Barbosa Porto', Maria Marlene Marques Ávila1', Cecília Galvão² Maria do Socorro de \\ Sousa $^{3}$ \\ ${ }^{1}$ Universidade Estadual do Ceará, Brasil. valberto.porto@uece.br; marlene.avila@uece.br \\ ${ }^{2}$ Instituto de Educação/Universidade de Lisboa. Portugal. cgalvao@ie.ulisboa.pt \\ ${ }^{3}$ Universidade Federal do Ceará. sousams3@gmail.com
}

\begin{abstract}
Resumo. A experiência de pesquisa pode iniciar-se como uma curiosidade e transformar-se em algo valioso, numa perspectiva investigativa. Iniciando-se com participação inopinada no $6^{\circ}$ Congresso de Investigação Qualitativa, o primeiro autor desenvolveu formação, que, no seu senso, levou-o a encontrar um caminho seguro para, com a segunda autora, sua orientadora, conduzirem sua Tese. O objetivo deste artigo é apresentar o relato da experiência de uso inicial do software webQDA, na elaboração de um processo de investigação, de modo que este trabalho possa ajudar outras pessoas a realizar atividades da mesma natureza. Usou-se, para sistematizar o relato da experiência, a narrativa autobiográfica como base metodológica, realizando-se uma reflexão crítica e sistematizadora a respeito do desenvolvimento cronológico e sobre o como e o por que desta experiência, buscando-se, como resultados, caracterizar a formação cursada pelo primeiro autor como descortinadora dos conhecimentos sobre o software e organizadora, no sentido de estruturar com coerência interna suas questões de investigação. Enfim, procurou-se, com este artigo curto, demonstrar ser o webQDA uma matriz potente, proporcionando ao pesquisador e sua orientadora arrumarem a investigação, no sentido de aplicar de forma adequada o recurso da análise de conteúdo ao desenvolvimento da pesquisa.
\end{abstract}

Palavras-chave: Sistematização de Experiência; Narrativa Autobiográfica; Uso de Software; Formação Cursada; Saúde Coletiva.

\section{THE INITIAL USE OF WEBQDA SOFTWARE TO SUPPORT THE CONDUCT OF A THESIS}

\begin{abstract}
The research experience can start out as a curiosity and turn into something valuable, from an investigative perspective. Beginning with unexpected participation in the 6th Congress of Qualitative Research, the first author developed training, which, in his sense, led him to find a safe way for, with the second author, his supervisor, to conduct his Thesis. The objective of this article is to present the report of the experience of initial use of the webQDA software, in the elaboration of an investigation process, so that this work can help other people to carry out activities of the same nature. In order to systematize the experience report, the autobiographical narrative as a methodological basis, carrying out a critical and systematic reflection on the chronological development and on the how and why of this experience, seeking, as a result, to characterize the training taken by the first author as an explorer of knowledge about the software and organizer, in the sense of structuring his research questions with internal coherence. Finally, we tried, with this short article, to demonstrate that webQDA is a powerful matrix, providing the researcher and his supervisor to organize the investigation, in order to properly apply the content analysis resource to the research development.
\end{abstract}

Keyword: Systematization of Experience; Autobiographical Narrative; Use of Software; Attended Training; Collective Health. 


\section{INTRODUÇÃO}

Abordamos neste artigo a sistematização do início da experiência no uso do software webQDA (Costa, Moreira \& Souza, 2019) na elaboração da Tese de doutorado do primeiro autor, considerando a contribuição significativa deste instrumento de pesquisa qualitativa na facilitação das tarefas de organização, análise e interpretação dos dados, demandados por aquele trabalho, que é considerado um dos requisitos para obtenção do título de doutor, em uma universidade pública do Ceará, Brasil.

Esta sistematização tem como embasamento teórico-metodológico o que nos afirma Palma (1992, p. 9), que "la sistematización se incluye en esa corriente ancha que busca comprender y tratar con lo cualitativo en la realidad". Ainda, segundo Holliday (2006, p. 22) sistematizar é "apropriar-se da experiência vivida e dar conta dela, compartilhando com os outros o aprendido" aludindo que se trata da "reconstrução ordenada da experiência" (IBID).

O recurso utilizado para relatar esta experiência foi o da narrativa autobiográfica por ater-se ao pressuposto "de que, ao narrarmos episódios com significado, os analisaremos de uma forma contextualizada, tentando que essa análise ponha em evidência emoções, experiências ou pequenos fatos marcantes, dos quais antes não nos tínhamos apercebido" (Freitas \& Galvão, 2007, p. 2).

O marco inicial desta experiência começou no dia anterior a abertura do $6^{\circ}$ Congresso lberoAmericano em Investigação Qualitativa (CIAIQ), que foi realizado em Salamanca - Espanha, nas instalações do Colégio Maestro Ávila, de 12 a 14 de julho de 2017, quando me matriculei no webQDA day e me empolguei com o uso do software na minha Tese, sabendose que "o webQDA é um software de análise de texto, vídeo, áudio e imagem que funciona num ambiente colaborativo e distribuído com base na internet" (Souza \& Col, 2016, p. 4).

O clímax da experiência se deu por conta da matrícula no curso avançado sobre o uso do software, a ser realizado em Aveiro, quando em 13/11/2018, o primeiro autor reuniu-se com o professor encarregado daquele curso, que o orientou quanto à definição de um roteiro para o seu estudo, exercício que se configurou como ponto de partida, ou seja, o fio da meada para o desenvolvimento da Tese, subsidiada pelo emprego do software, finalizando os aspectos abordados neste artigo. 
Destarte foram questões norteadoras da construção dessa narrativa:

1) Quais foram os momentos que se configuraram como de formação para aquisição de conhecimento sobre o uso do webQDA?

2) Por que se optou pelo uso do software?

3) Com que finalidade se decidiu sistematizar este aprendizado?

Em suma, o objetivo deste artigo é apresentar o relato da experiência do uso inicial do software webQDA, na elaboração de um processo de investigação, de modo que este trabalho possa ajudar outras pessoas a realizar atividades da mesma natureza.

\section{BASES METODOLÓGICAS}

Este artigo se caracteriza como um relato de experiência em seu contexto, se fazendo para compreender melhor os seus pressupostos filosóficos: ontologicamente, considerando-se a "realidade e suas características"; epistemologicamente, quanto ao se "o saber é conhecido - por meio de experiência subjetiva das pessoas"; e axiologicamente, permitindo aos pesquisadores qualitativos "que os seus valores sejam conhecidos em um estudo" (Creswell, 2014, p. 32 e 33).

Desse modo, baseia-se na técnica de sistematizar por meio de um processo de reflexão crítica, organizada e diligente, para reconstruir, ordenadamente a experiência sobre o uso de um software, o webQDA, na Tese do primeiro autor, partindo-se da premissa que, segundo Holliday (2006, p.21),

- experiências são processos sociais dinâmicos: em permanente mudança e movimento. São também processos sociais complexos, em que se interrelacionam, de forma contraditória, um conjunto de fatores objetivos e subjetivos:

- as condições do contexto em que se desenvolvem;

- situações particulares a enfrentar-se;

- ações dirigidas para se conseguir determinado fim;

- percepções, interpretações e intenções dos diferentes sujeitos que intervêm no processo;

- resultados esperados e inesperados que vão surgindo; 
- relações e reações entre os participantes.

São processos particulares que fazem parte de uma prática social e histórica mais geral igualmente dinâmica, complexa e contraditória.

Estamos falando, então, de experiências vitais, carregadas de uma enorme riqueza acumulada de elementos que, em cada caso, representam processos inéditos e irrepetíveis. É por isso que é tão apaixonante a tarefa de compreendê-las, extrair seus ensinamentos e comunicá-los.

Para sistematizar as informações usou-se o método da análise narrativa (Galvão, 2005; 2018; Onocko Campos \& Furtado, 2008; Dutra, 2002), aplicando-se a técnica da narrativa autobiográfica como a forma de descortinar a vivência do pesquisador no uso do webQDA.

A investigação narrativa está respaldada nos ensinamentos obtidos na disciplina sobre Análise Narrativa, cursada no Doutoramento Intercalar, oferecido pelo Curso de Doutoramento em Didática das Ciências, do Instituto de Educação (IE), da Universidade de Lisboa (ULISBOA), ministrado pela terceira autora deste artigo, que - com base no livro de Isabel Allende, 'Paula' - iniciou sua aula sobre narrativa com a citação: "A minha vida faz-se ao contá-la e a minha memória fixa-se com a escrita; o que não ponho em palavras no papel, o tempo apaga-o.

A escrita é uma longa introspecção, é uma viagem até às cavernas mais obscuras da consciência, uma lenta meditação" (Galvão, 2005, p. 327; 2018, p. 2), o que demonstra a importância de se textualizar uma experiência, para que se registre como história.

Assim sendo, complementando o processo investigativo com a técnica da narrativa usar-seá as ideias de Stephens (1992) encontradas em Galvão (2005, p. 328), por meio dos seus

três componentes: História - abrange as personagens envolvidas em determinados acontecimentos, num espaço e tempo determinados e possibilita uma primeira interpretação do que é contado; Discurso - forma específica como qualquer história é apresentada; Significação - uma interpretação de segundo nível que o ouvinte/leitor/espectador obtém a partir do inter-relacionamento da história e do respectivo discurso. 
Desta forma, a técnica empregada parte do pressuposto de que toda história, "tem um começo, um meio e um fim" (Onocko Campos \& Furtado, 2008, p. 1092), demonstrando que o registro histórico se faz pela linguagem textualizada, conforme a vivência experimentada, que, "trazendo o sentimento à tona, revela também a situação, ou o contexto situacional, já que todos estão relacionados entre si" (Dutra, 2002, p. 373).

A textualização se fará no sentido empregado por Levi-Strauss, que, no seu livro Tristes Trópicos, narra sobre o desafio de conhecer algo novo, diferente do seu mundo, afirmando sobre a sua aventura no Brasil, que "nesses terrenos, que sobrepujam as duas margens do rio Tibagi, a cerca de mil metros acima do nível do mar, tive o meu primeiro contato com os selvagens" (Levi-Strauss, 1993, p. 142) ao que comparo à minha chegada ao continente europeu, para em Salamanca-Espanha, no Colégio Maestro Ávila, ter o meu primeiro contato com algo que não conhecia, o webQDA, o que me desafiou a querer me aprofundar no domínio de algo que julguei útil para desenvolver meus estudos.

Entrementes se fará também na conotação dada por Batenson, o qual narra no seu livro Metadiálogos, o diálogo do pai com uma filha, no qual eu me coloco no papel da menina, que espera da mãe a ajuda na arrumação das suas coisas, já que como afirma seu pai "há infinitamente mais caminhos desarrumados, e portanto as coisas tenderão sempre para desarrumadas e misturadas" (Batenson, 1996, p. 16), o que obedece à lei física da entropia, só contrariada se empregarmos, como no nosso caminhar de uso do webQDA, o esforço, orientado por uma matriz segura, que por meio da formação proporcionada nos mostrou o rumo coerente da organização, análise e interpretação dos nossos achados, com base nos seus pilares: fonte, codificação e questionamento, possibilitando ao pesquisador "editar, visualizar, interligar e organizar documentos. Simultaneamente pode criar categorias codificar, controlar filtrar e questionar os dados com o objetivo de responder às questões que emergem da sua investigação" (Costa \& Amado, 2018, p. 31).

As atividades realizadas e as publicações advindas do software webQDA oportunizará a análise e interpretação das informações a serem discutidas juntamente com os resultados obtidos.

\section{RESULTADOS E DISCUSSÃO}

Os resultados baseiam-se nas formações cursadas no intervalo de tempo considerado, oferecidas pelo software, funcionando como uma matriz arrumadora do conhecimento, na 
acepção de Batenson (1996).

As formações desenvolvidas, desafio para conhecer o novo na acepção de Levi-Strauss (1993), cronologicamente, foram as seguintes, Quadro 1.

Quadro 1: Formações desenvolvidas proporcionadas pelo webQDA

\begin{tabular}{|c|c|c|c|}
\hline Ano & Dia/Mês & Local & Atividade de Formação \\
\hline \multirow{6}{*}{2017} & $11 / 07$ & Salamanca $/ 6^{\circ} \mathrm{CIAIQ}$ & webQDA day Análise Qualitativa Suportada por Software \\
\hline & $12 / 07$ & Idem & $\begin{array}{l}\text { workshop Introdução à Análise Qualitativa Suportada pelo } \\
\text { Software webQDA }\end{array}$ \\
\hline & $\begin{array}{l}07 e \\
08 / 08\end{array}$ & Fortaleza/UNIFOR & $\begin{array}{l}\text { webQDA Meeting Análise Qualitativa Suportada por } \\
\text { Software }\end{array}$ \\
\hline & $21 / 09$ & Aveiro/Ludomedia & $\begin{array}{l}\text { webinar online webQDA: Mapas de Códigos, Exportação } \\
\text { de Relatórios e Fluxo de Trabalho }\end{array}$ \\
\hline & $09 / 11$ & Idem & $\begin{array}{l}\text { Curso e-learning online Estudo de Caso com o apoio do } \\
\text { software webQDA }\end{array}$ \\
\hline & $19 / 12$ & Idem & webinar online Processo de Categorização no webQDA \\
\hline \multirow{8}{*}{2018} & $10 / 01$ & idem & $\begin{array}{l}\text { webinar Organização e Codificação Automática de Dados } \\
\text { com o webQDA }\end{array}$ \\
\hline & $\begin{array}{l}29 / 01 \text { a } \\
05 / 02\end{array}$ & Idem & $\begin{array}{l}\text { Curso online E-learning Investigação Qualitativa com o } \\
\text { webQDA: Fontes, Codificação, Questionamento e } \\
\text { Colaboração }\end{array}$ \\
\hline & $05 / 02$ & Idem & $\begin{array}{l}\text { webinar Critérios de Construção e Avaliação de Artigos } \\
\text { em Investigação Qualitativa (CCAAIQ) }\end{array}$ \\
\hline & $23 / 02$ & Aveiro/UNAVE & $\begin{array}{l}\text { Curso Avançado Análise Qualitativa com Apoio do } \\
\text { Software webQDA - não realizado }\end{array}$ \\
\hline & $10 / 07$ & Fortaleza/7º CIAIQ & $\begin{array}{l}\text { webQDA day Análise Qualitativa com o apoio do software } \\
\text { webQDA }\end{array}$ \\
\hline & $\begin{array}{l}10 a \\
20 / 09\end{array}$ & Aveiro/Ludomedia & $\begin{array}{l}\text { Curso online E-learning Investigação Qualitativa com o } \\
\text { webQDA: Fontes, Codificação, Questionamento e } \\
\text { Colaboração - } 2^{a} \text { edição }\end{array}$ \\
\hline & $11 / 09$ & $\begin{array}{l}\text { Brasília/Instituto de } \\
\text { Química/UNB }\end{array}$ & $\begin{array}{l}\text { Curso de Formação "Introdução ao software de Análise } \\
\text { Qualitativa webQDA }\end{array}$ \\
\hline & $13 / 11$ & $\begin{array}{l}\text { Aveiro/Departamento } \\
\text { de Educação e } \\
\text { Psicologia/UNAVE }\end{array}$ & $\begin{array}{l}\text { Curso Avançado Análise Qualitativa com Apoio do } \\
\text { Software webQDA - Dia de trabalho presencial }\end{array}$ \\
\hline
\end{tabular}

Fonte: o próprio autor, 2020

Há de se considerar que a narrativa autobiográfica, na acepção da quarta autora é um recurso metodológico em ascensão, no cenário da pesquisa qualitativa, por demais oportuno, para conduzir discussões dessa natureza.

A reflexão crítica e sistematizadora a respeito do desenvolvimento cronológico exposto no quadro 1 e sobre o como e o por que desta experiência será abrangida por uma discussão pormenorizada dos resultados supra apresentados, a ser realizada oportunamente em um artigo completo.

Entretanto, espera-se demonstrar, nesta parcial apreciação, que a formação cursada, 
oferecida pelo webQDA, foi uma matriz potente, para gerar um corpus de dados e processar a análise de conteúdo (Bardin, 2016; Costa \& Amado, 2018) na elaboração da Tese do primeiro autor sob a orientação da segunda autora.

Em suma, a partir desta formação, o primeiro autor encontrou um caminho coerente de arrumar os seus questionamentos dentro de um quadro de coerência interna da análise da investigação, subsidiado pela formação cursada, quadro 2.

Quadro 2: Coerência Interna da Análise da Investigação (Costa, Neri de Souza \& Neri de Souza, 2016, p. 136).

\begin{tabular}{|c|c|c|c|c|}
\hline $\begin{array}{c}\text { Questões de } \\
\text { Investigação }\end{array}$ & $\begin{array}{c}\text { Dimensões/Subdimensões } \\
\text { de Análise }\end{array}$ & $\begin{array}{c}\text { Categorias de } \\
\text { Análise }\end{array}$ & Subcategorias & $\begin{array}{c}\text { Observações, } \\
\text { Expectativas e } \\
\text { Perguntas Subsidiárias }\end{array}$ \\
\hline $\begin{array}{c}\text { Questão 1 } \\
\text { Questão 2 } \\
\ldots\end{array}$ & & & & \\
\hline
\end{tabular}

Em síntese, espera-se que essa experiência sirva de exemplo para outros pesquisadores utilizarem este valioso recurso computacional, como o é o software webQDA.

\section{CONSIDERAÇÕES FINAIS}

O presente artigo é um relato parcial da experiência do primeiro autor no uso do software webQDA, a qual, na sua óptica, foi uma experiência exitosa por ter lhe apontado o rumo do desenvolvimento da sua Tese de doutorado.

Estas considerações apontam para a parcialidade das conclusões, as quais serão explicitadas, a partir de uma discussão pormenorizada das atividades enumeradas no quadro 1 e consumadas no quadro 2.

\section{REFERÊNCIAS}

Bardin, L. (2016). Análise de Conteúdo. São Paulo: Edições 70.

Batenson, G. (1996). Metadiálogos Trajectos. Lisboa: Gradiva.

Costa, A. P. Souza, F. N. de. Souza, D. N. de. (2016). Investigação Qualitativa Inovação, Dilemas e Desafios, Volume 1. Aveiro: Ludomedia.

Costa, A. P. Amado, J. (2018). Análise de Conteúdo Suportada por Software. Aveiro, Ludomedia.

Costa, A. P. Moreira, A., \& Souza, F. N. de. (2019). webQDA - Qualitative Data Analysis. Aveiro - Portugal: Aveiro University and MicrolO. Retrieved from www.webqda.net

Creswell, J. W. (2014). Investigação qualitativa e projeto de pesquisa: escolhendo entre cinco abordagens. $3 a$ ed. Porto Alegre: Penso. 
Dutra, E. (2002). A narrativa como uma técnica de pesquisa fenomenológica. Natal: Revista Estudos de Psicologia, Volume 7, Número 2, páginas $371-378$.

Freitas, D. de. Galvão, C. (2007). O uso de narrativas autobiográficas no desenvolvimento profissional de professores. Rio de Janeiro: Ciências \& Cognição; Ano 04, Vol. 12.

Galvão, C. Narrativas em Educação. (2005). Revista Ciência \& Educação, Bauru, v. 11, n. 2, p. 327-345.

Galvão, C. (2018). Narrativas na Educação. Apresentação em PDF. Lisboa: Instituto de Educação/Universidade de Lisboa.

Holliday, O. J. (2006). Para Sistematizar Experiências. Brasília: Ministério do Meio Ambiente.

Levi-Strauss, C. (1993). Tristes Trópicos. Lisboa: Edições 70.

Onocko Campos, R. N. Furtado, J. P. (2008). Narrativas: utilização na pesquisa qualitativa em saúde. São Paulo: Revista de Saúde Pública, Volume 42, Número 6, p. 1090 a 1096.

Palma, D. (1992). Estado Actual de la Sistematizacón. La Sistematización como estratégia de conocimiento. Santiago do Chile: Conselho de Educação de Adultos da América Latina (CEAAL).

Souza, F. N. de. Costa, A. P. Moreira, A. Souza, D. N. de. Freitas, F. (2016). webQDA - Manual de Utilização Rápida. Aveiro: Universidade de Aveiro Editora. 